\title{
Screening for blood lead level in reproductive age group individuals in Kathmandu
}

\author{
Vivek Pant ${ }^{1}$, Keyoor Gautam ${ }^{2}$, Devish Pyakurel ${ }^{2}$, Vijay Sharma ${ }^{3}$, Nutan \\ Sharma ${ }^{4}$, Santosh Pradhan ${ }^{1}$, Abha Shrestha ${ }^{2}$ \\ ${ }^{\prime}$ Department of Clinical Biochemistry, Samyak Diagnostic, Jawalakhel , Lalitpur, Nepal \\ ${ }^{2}$ Department of Pathology, Samyak Diagnostic, Jawalakhel, Lalitpur, Nepal \\ ${ }^{3}$ Department of Biochemistry, Institute of Medicine, Tribhuvan University Teaching Hospital, Maharajgunj, Nepal \\ ${ }^{4}$ Department of Obstetrics and gynecology, Alka IVF Centre, Jawalakhel, Lalitpur, Nepal
}

\section{Keywords:}

Blood lead level;

Lead screening;

Reproductive age ;

\begin{abstract}
Background: Elevated blood lead level is associated with serious, often irreversible, health consequences. At present, the safe level of blood lead cannot be ascertained since the emerging data indicate the toxic potential to the human organ system at a low level that was previously considered safe. Screening for blood lead levels is not in regular practice in Nepal. This study is designed to evaluate the prevalence of detectable blood lead levels in the reproductive age group of the Nepalese population that represents the wide local population.
\end{abstract}

Materials and Methods: 170 reproductive age group individuals (20 to 49 years) attending Samyak Diagnostic Pvt Ltd and Alka IVF and fertility centre for regular health checkups were included in this study for blood lead level analysis. The participants were categorized as normal or sub-fertile. Blood lead level was estimated using anodic stripping voltammetry.

Results: In total study participants, $28.8 \%$ of males and $25.8 \%$ of females had BLL $\geq 3.0 \mu \mathrm{g} / \mathrm{dL}$. The minimum detectable blood lead level in both males and females was $3.3 \mu \mathrm{g} / \mathrm{dL}$ while the maximum blood lead level was higher in males $(15.5 \mu \mathrm{g} / \mathrm{dL})$ than in females $(8.4 \mu \mathrm{g} / \mathrm{dL})$. The median blood lead level of the sample population was $3.7(4.8-6.9) \mu \mathrm{g} / \mathrm{dL}$. There was no significant difference in blood lead level between gender $(\mathrm{p}=0.108)$.

Conclusion: It is justifiable to screen for blood lead levels in the reproductive age group individual in Nepal.

\section{Correspondence:}

Dr. Vivek Pant, $M D$

Department of Clinical Biochemistry.

Samyak Diagnostic Pvt. Ltd. Lalitpur, Nepal

ORCID:0000-0002-3967-1851

Email:drvpant@gmail.com

Received : June $27^{\text {th }} 2021$; Accepted : August $8^{\text {th }} 2021$

Citation: Pant V, Gautam K, Pyakurel D, Sharma V, Sharma N, Pradhan S, Shrestha A.. Screening for blood lead level in reproductive age group individuals in Kathmandu. Journal of Pathology of Nepal. 2021;11(2):1802-5. DOI:10.3126/jpn.v11i2.38102

Copyright: This is an open-access article distributed under the terms of the Creative Commons Attribution 4.0 International License, which permits unrestricted use, distribution, and reproduction in any medium, provided the original author and source are credited.

\section{INTRODUCTION}

Lead is a toxic metal that adversely affects many physiologic functions through multiple biochemical mechanisms. ${ }^{1}$ Because lead toxicity often presents with nonspecific signs and symptoms, the diagnosis must be suspected based on exposure history and other associated complaints such as unexplained abdominal pain, headache, difficulty concentrating, and anemia. Lead toxicity is confirmed only by laboratory testing.

The prevalence of high blood lead levels (BLL) in reproductive age group individuals is difficult to ascertain because of limited data. The existing data and research 
findings suggest that it remains an important environmental and public health problem in developing nations. The case definition for an elevated BLL is now defined as $\geq 5 \mu \mathrm{g} / \mathrm{dL}$ (previously $\geq 10 \mu \mathrm{g} / \mathrm{dL}$ )by the Centers for Disease Control and Prevention (CDC) of the United States of America (US) however no limit is safe. ${ }^{2}$ Elevated BLL is associated with higher all-cause mortality in both men and women. Even the BLL below $10 \mu \mathrm{g} / \mathrm{dL}$ is associated with deaths from cardiovascular diseases in the general population. ${ }^{3}$ Thus, lead risk assessment is necessary as the previously recognized "safe" level of lead is also being found to be associated with negative health outcomes.

The changes in public health policy have led to substantial declines in the prevalence of lead toxicity in developed countries, however, the cases of lead toxicity remain public health problem in developing nations. Routine screening for blood lead levels in defined groups such as pregnant women and children is not recommended so far. Similarly, risk assessment of lead exposure as part of a comprehensive health risk assessment by healthcare professionals in the first contact with the patient is lacking in our settings.

According to the World Health Organization (WHO) report, about one half of the burden of disease from lead exposure occurs in the South- East Asian region. ${ }^{4}$ The majority of lead exposure occurs in the workplace, home environment, environmental exposure, and unintentional oral ingestion of material contaminated with lead. Recently, there have been reports on a high level of blood lead in various subgroups of the Nepalese population. Two different Kathmandu-based studies conducted in primary school children and toddlers reported detectable BLL in $63 \%$ and $64.4 \%$ of children respectively. ${ }^{5,6}$ Similarly, a study which was done among rag pickers in Kathmandu reported a mean BLL of $11.6 \mu \mathrm{g} /$ $\mathrm{dL}$ in participants.

Early identification of elevated BLL is the key to reducing the long-term effects of lead exposure. The current status of BLL in the Nepalese reproductive age group population, which represents a wide local population, is not available. A study of BLL in this group of population is the best way to screen society and be aware of lead and its health hazards.

\section{MATERIAL AND METHODS}

A cross-sectional observational study to screen for high blood lead levels was done among 170 reproductive age group (20 to 49 years) individuals, through convenience sampling, who attended Samyak Diagnostic Pvt Ltd and Alka IVF and fertility center for regular health checkups during March 2021- June 2021. Participants who routinely took any medication or Ayurvedic drugs were excluded from this study. The participants were categorized as fertile (normal) or sub-fertile according to the clinical history (including pregnancy and number of children) and clinician's prescription (if they had attended an infertility clinic for being unable to conceive naturally).

All the participants provided written informed consent for this study. The questionnaire was used in this study which consisted of participants' demographic data, clinical information regarding fertility, major health issues, and use of drugs and Ayurvedic medicines.

Whole blood collected in Ethylenediaminetetraacetic acid (EDTA) tube was used for the BLL analysis irrespective of the fasting state. Measurement of BLL was done using the Lead Care II instrument (Magellan Diagnostics Inc., N. Billerica, Massachusetts, USA). Lead care II is a Clinical Laboratory Improvement Amendments (CLIA) waived point of care system that relies on using anodic stripping voltammetry to detect BLL in whole blood. After mixing the whole blood with the treatment reagent, the red blood cells are lysed and lead is released and collected on the sensor by the potential applied from the analyzer. After 3 minutes the analyzer measures the amount of lead collected on the sensor and displays the result in $\mu \mathrm{g} / \mathrm{dL}$. The quality control in the present study was maintained with two levels of controls (higher and normal), the target range for which was specified by the manufacturer. The minimal limit of detection for this instrument is $3.0 \mu \mathrm{g} / \mathrm{dL}$. Any result above $\geq 5 \mu \mathrm{g} / \mathrm{dL}$ is elevated blood lead level.

The data was entered to the SPSS Version 18.0 for Windows (SPSS Inc., Chicago, IL, USA) and Shapiro's normality test was performed. The data failed the normality test. Thus, the result is presented in the median and the 25- and 75 percentiles (i.e., the interquartile range)The Mann-Whitney rank test was used to compare the gender difference in blood lead level. A P-value of $<0.05$ was considered statistically significant. Ethical approval to conduct this study was taken from the Nepal health research council (Protocol number: 209/2021 P)

\section{RESULTS}

The majority of individuals in the normal (fertile) and subfertile group had detectable blood lead levels (Table 1, fig. $1)$. When both normal and sub-fertile group was included, $28.8 \%$ of male and $25.8 \%$ of female participants had BLL $\geq 3 \mu \mathrm{g} / \mathrm{dL}$. The minimum detectable BLL in both males and females was $3.3 \mu \mathrm{g} / \mathrm{dL}$ while the maximum elevated BLL was higher in males $(15.5 \mu \mathrm{g} / \mathrm{dL})$ than in females $(8.4 \mu \mathrm{g} /$ $\mathrm{dL}$ ) as shown in figure 1 . There were six individual (3.5\%) with elevated BLL above $10 \mu \mathrm{g} / \mathrm{dL}$ and all was male. This is considered to be high according to US CDC guidelines.

The median BLL of the sample population was 3.7(4.8 -6.9) $\mu \mathrm{g} / \mathrm{dL}$. The mann-Whitney rank test confirmed that there is no significant difference in BLL between males and females $(\mathrm{p}=0.108)$. 
Table 1: " Blood lead level in normal and sub-fertile participants"
Number of total participants $(n=170)$
Normal
$(\mathrm{n}=115)$
Sub-fertile
$(\mathrm{n}=55)$
Male $(n=68)$
Female $(n=47)$
$\underset{(n=13)}{\text { Male }}$
Female
$(n=42)$
Number of participants with $\mathrm{BLL}(\geq 3.0 \mu \mathrm{g} / \mathrm{dL})$
$(\mathrm{n}=48)$
$41.7 \%$
$(\mathrm{n}=37)$
$(\mathrm{n}=1)$
$(\mathrm{n}=7)$
$32.2 \%$
$1.8 \%$
$12.7 \%$

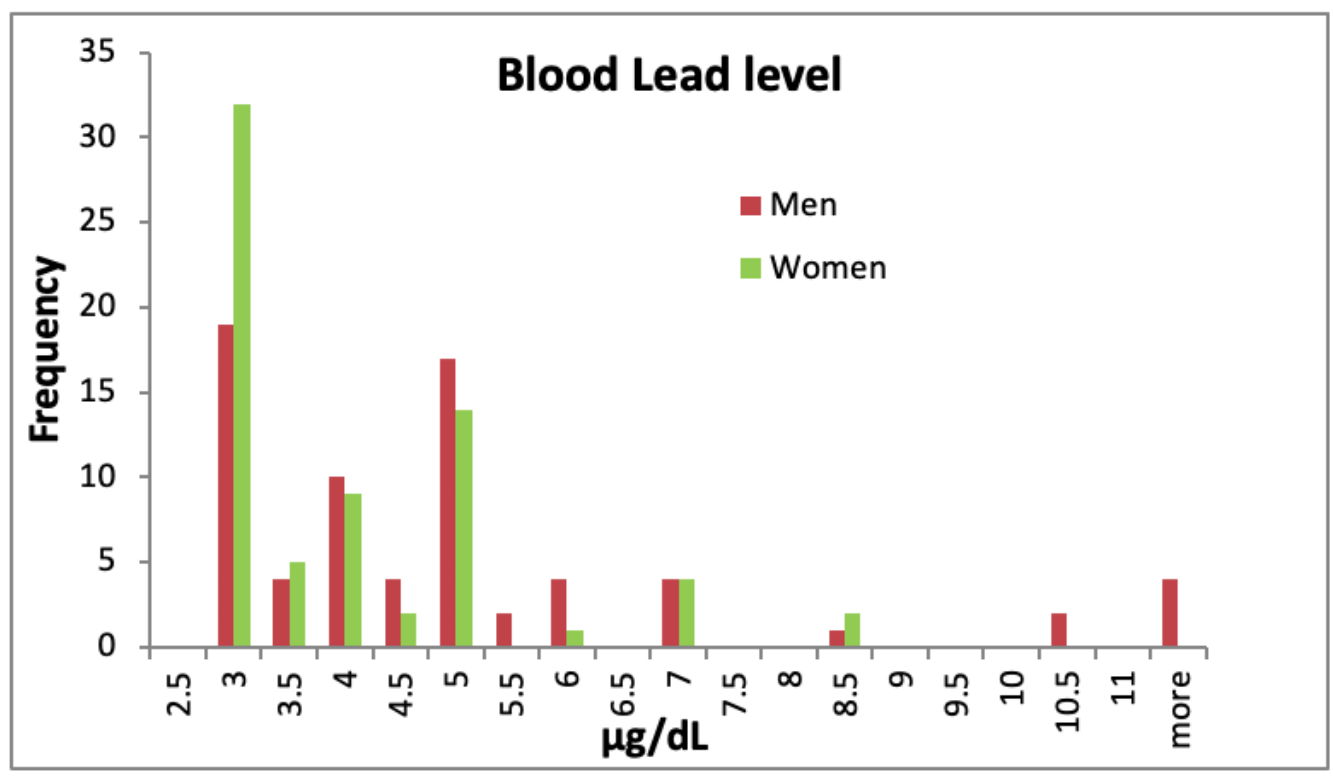

Figure 1:BLL compared in male and female

\section{DISCUSSION}

Lead has no biological function and its presence can cause irreversible damage to body organs. The US CDC now acknowledges that there is no safe level of lead exposure. ${ }^{2}$

The majority of reproductive age group male and female had BLL $(>3.0 \mu \mathrm{g} / \mathrm{dL})$ in our study. Similar findings have been reported from other Asian cities. In an adult population of an Indian city and Eastern Iran, the detectable BLL in study participants was $49 \%$ and $45 \%$ respectively. ${ }^{8,9}$

Detectable BLL in this significant number of participants in our study may be attributed to low socioeconomic status, substandard housing that may contain deteriorated leadbased paint, handling of batteries and electronic equipment, use of lead-glazed cooking vessels, and folk remedies. All these causes are reported as a source of lead exposure in Nepal. ${ }^{7,10,11}$

The reproductive age group population in this study, which is not exposed to lead occupationally, has still detectable BLL and is at high risk of developing lead toxicity. There are several reports which indicated that lead has toxic effects on human male reproduction by declining libido, spermatogenesis, semen quality, and hormonal production along with its regulation. ${ }^{12,13}$ Exposure of pregnant women to high levels of lead can cause miscarriage, stillbirth, premature birth, and low birth weight, as well as minor malformations in young ones. ${ }^{14}$ Also, there is evidence suggesting that having a detectable BLL $(\geq 1 \mu \mathrm{g} / \mathrm{dL})$ is associated with smaller body size in children as young as $2-3$ years..$^{15}$

The main potential benefit of screening for high lead levels is finding cases and preventing further exposure before symptoms of lead toxicity develop. There is a potential public health benefit in finding unknown sources of lead in the community, which can help protect others. Our study found sufficient evidence to say that screening for high lead levels in the reproductive age group person should be advocated.

There are a few limitations of this study. The average value of BLL in the reproductive age group represents an overestimate, because the limit of quantification for this Lead Care II instrument is $3.0 \mu \mathrm{g} / \mathrm{dL}$. Nevertheless, the prevalence of detectable BLLin in both male and female 
populations is high. Similarly, various dietary practices and housing conditions, that may have a role in the high BLL, were not included in the questionnaire. Only the information about the use of over-the-counter drugs such as Ayurvedic medication that has the potential to increase BLL ${ }^{10}$ was received from each participant and if found were excluded from this study.

There are key gaps in the evidence base regarding screening for elevated blood lead levels. The clinicians and policymakers should be encouraged to review guidelines of national and international organizations regarding health protocol for lead poisoning. It is necessary to study and document the average blood lead levels and trace the route of exposure in all cases across different age groups throughout the country.

\section{CONCLUSIONS}

It is justifiable to screen for blood-lead levels in the reproductive age group individual in Nepal. Policymakers are encouraged to review recommendations of other organizations, including national scientific publications regarding lead and its health hazard.

\section{Acknowledgement}

Authors would like to thank Mrs. Sarada Pahari for her help during sample collection.

\section{Conflict of interest: None}

\section{REFERENCES}

1. Flora G, Gupta D, Tiwari A. Toxicity of lead: a review with recent updates Interdisciplinary toxicology. 2012; 5:47. $\underline{\text { Crossref }}$

2. Advisory Committee on Childhood Lead Poisoning Prevention of the Centers for Disease Control and Prevention. Low Level Lead Exposure Harms Children: A Renewed Call for Primary Prevention. (Cited on 8th June 2021) Website

3. Bellinger DC. The protean toxicities of lead: new chapters in a familiar story. International journal of environmental research and public health. 2011; 8:2593-628.

4. WHO. Lead poisoning and health. 2004. (Cited on 10th June 2021) Website

5. Sherchand O, Mehta KD, Poudel P, et al. Blood Lead Levels of Primary School Children in Kathmandu Municipality, Nepal. Journal of Institute of Medicine. 2014; 36. Website

6. Dhimal M, Karki KB, Aryal KK, et al. High blood levels of lead in children aged 6-36 months in Kathmandu Valley, Nepal: A crosssectional study of associated factors. PloSone.2017;12:e179233. $\underline{\text { Crossref }}$
7. Gautam K, Pant V, Pradhan S, et al. Blood lead levels in rag-pickers of Kathmandu and its association with hematological and biochemical parameters. EJIFCC. 2020;31:125. Website

8. Chambial S, Shukla KK, Dwivedi S, et al. Blood lead level (BLL) in the adult population of Jodhpur: a pilot study. Indian Journal of Clinical Biochemistry. 2015 ;30:357-9. Crossref

9. Nakhaee S, Amirabadizadeh A, ZarbanA, et al. The reference value of blood lead level among the general adult population of eastern Iran. Journal of Environmental Science and Health, Part A. 2019;54:128792. $\underline{\text { Crossref }}$

10. Pant V, Gautam K, Pyakurel D, Shrestha A, Pradhan S, Joshi N. Broadening the list of differential diagnosis for acute abdomen-a case report from Nepal. EJIFCC. 2020;31:347. Website

11. Gottesfeld P, Pokhrel D, Pokhrel AK. Lead in new paints in Nepal. Environ Res. 2014;132:70-5. Crossref

12. Telisman S, Cvitković P, Jurasović J, et al. Semen quality and reproductive endocrine function in relation to biomarkers of lead, cadmium, zinc, and copper in men. Environmental health perspectives. 2000;108:45-53. $\underline{\text { Crossref }}$

13. Telišman S, Čolak B, Pizent A, et al. Reproductive toxicity of lowlevel lead exposure in men. Environmental research. 2007; 105:25666. $\underline{\text { Crossref }}$

14. Kumar S. Occupational and environmental exposure to lead and reproductive health impairment: an overview. Indian journal of occupational and environmental medicine. 2018; 22:128. Crossref

15. Cassidy-Bushrow AE, Havstad S, Basu N, et al. Detectable Blood Lead Level and Body Size in Early Childhood. Biol Trace Elem Res. 2016;171:41-7. Crossref 